\title{
Barrier dysfunction due to distinct defensin deficiencies in small intestinal and colonic Crohn's disease
}

\author{
J Wehkamp $^{1}$, M Koslowski ${ }^{2}$, G Wang ${ }^{2}$ and EF Stange ${ }^{1}$
}

Defensins are endogenous antibiotics with broad microbicidal activity. A disturbed antimicrobial defense, as provided by Paneth and other epithelial defensins, seems to be a critical factor in the pathogenesis of inflammatory bowel diseases. Conspicuously, there is a relative lack of Paneth-cell $\alpha$-defensins in ileal Crohn's disease (CD), both in the absence of a pattern recognition receptor nucleotide-binding oligomerization domain 2 (NOD2) frameshift mutation and, even more pronounced, in its presence. This deficit is independent of concurrent active inflammation and cannot be seen in active small intestinal ulcerative colitis (UC; pouchitis) as well as NOD2 wild-type graft vs. host ileitis. After intestinal transplantation, in case of NOD2 mutation, defensins are decreased before the onset of inflammation. In the majority of patients, the Paneth-cell deficiency is mediated by Wnt-TCF4, which suggests a disturbed Paneth-cell differentiation. In contrast, colonic $C D$ is characterized by an impaired induction of mucosal $\beta$-defensins, partly because of a low copy number of the $\beta$-defensin gene cluster. In both ileal and colonic $C D$, the lack in defensins results in a broadly diminished antibacterial killing by the mucosa, which can also be found independent of inflammation. In summary, the main disease locations can be linked to distinct mechanisms of epithelial barrier dysfunction.

\section{INTRODUCTION}

Multiple lines of evidence including studies in animal models and human patients support a current paradigm shift in the field of inflammatory bowel diseases (IBDs). Just until very recently, most of the research focussed on a possibly dysregulated adaptive immune function. Now, more and more data are arising, which suggests a primary disturbed barrier function allowing the entry of microorganisms and triggers mostly a secondary inflammatory response (Figure 1). Many scientists and especially physicians are becoming more critical about studying inflammatory cascades in mouse models, especially about uncritically extrapolating these findings to human patients. On the other hand, our knowledge of antimicrobial peptides and their function in innate and acquired immunity has increased exponentially over the past decade. A major group of cationic antimicrobial peptides in humans and other mammals are the defensins but there are others including lysozyme, cathelicidine LL-37, and antimicrobial antiproteases. It is evident that defects in such a highly conserved defense system could lead to disease. In this meeting-based review, we will focus on IBD, one key example of the clinical relevance of innate immunity. Recent reviews, including general overviews, ${ }^{1}$ have covered various aspects of the defensins in IBD, defensins in the gastrointestinal tract, ${ }^{2-4}$ and more specifically defensins in Crohn's disease (CD), ${ }^{5}$ which is an inflammatory disease of the intestinal tract. Inspired by recent studies, this review focuses on the various known mechanisms of gastrointestinal defensin deficiency as well as studies by other groups. We are convinced that the discovery of some of these innate immune defects in gastrointestinal diseases will not only change the appreciation of the importance of host innate defense, but also lead to new strategies of therapy.

\section{GASTROINTESTINAL ANTIMICROBIAL PEPTIDES}

Even though the gastrointestinal tract is constantly colonized and challenged by a multitude of different microorganisms, intestinal infection or translocation of bacterial agents is an exception, not the rule, and mostly limited to highly pathogenic bacteria or predisposing disease states. The permanent and constitutive production of different groups of antimicrobial peptides including defensins, defensin-like molecules (elafin

\footnotetext{
${ }^{1}$ Robert Bosch Hospital, Internal Medicine I, Stuttgart, Germany. ${ }^{2}$ Dr Margarete Fischer-Bosch Institute of Clinical Pharmacology and University of Tübingen, Stuttgart, Germany. Correspondence: J Wehkamp (jan.wehkamp@ikp-stuttgart.de) 


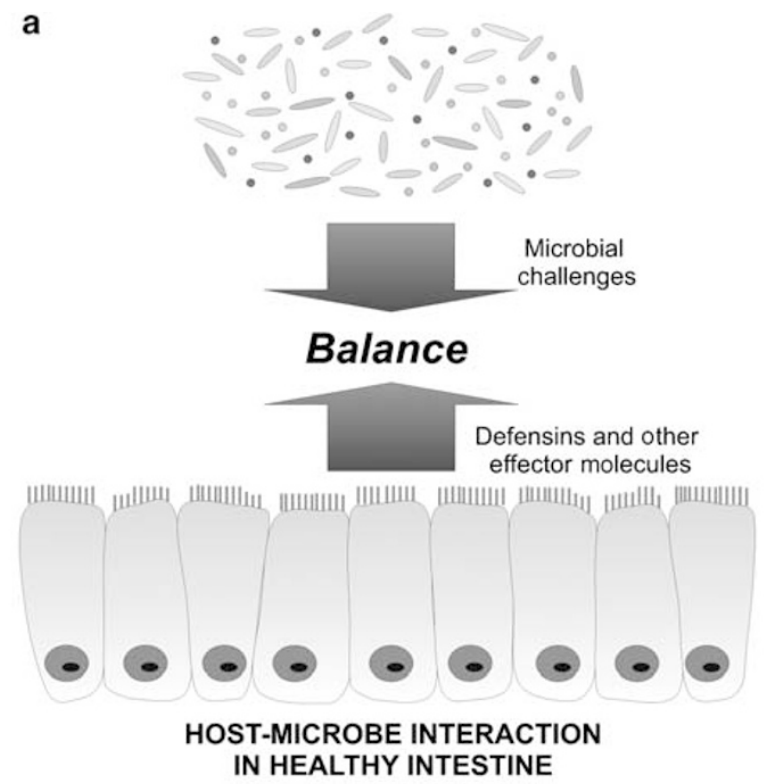

b

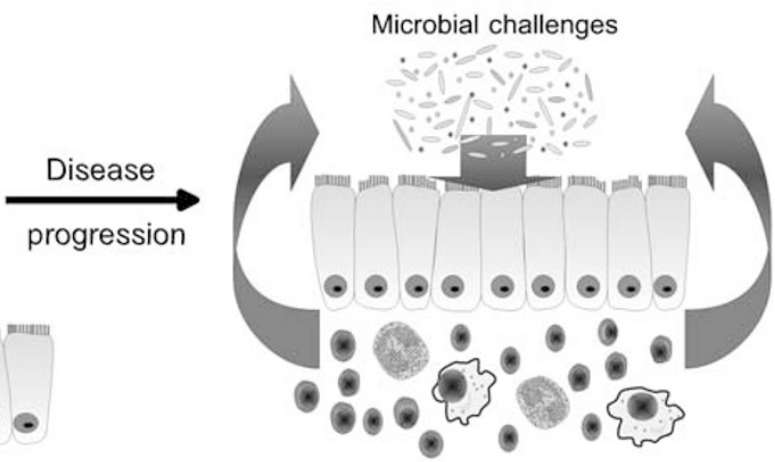

PROPOSED MODEL FOR CROHN'S DISEASE

Figure 1 Proposed model for the function of intestinal bacteria and host defensins in the pathogenesis and disease progression of Crohn's disease. (a) The healthy intestinal tract is characterized by a sensitive balance of host antimicrobial peptides and intestinal microbes. (b) In Crohn's disease this balance is disturbed. Owing to insufficient expression and function of antimicrobial defensin molecules intestinal microbes are able to invade the mucosa. With further progression of disease the bacterial influx provokes an inflammatory response. Reproduced from Wehkamp et al., ${ }^{4}$ with permission from Nature Publishing Group.

and secretory leukocyte protease inhibitor), cathelicidine LL-37, and other protective factors (e.g., mucus, trefoil factors, and many others) contributes in limiting invasion and adherence of pathogenic and commensal bacteria. Defensins are endogenous antibiotics with microbicidal activity against Gram-negative and Gram-positive bacteria, fungi, viruses, and protozoa. ${ }^{6}$ Although many defensins are mostly expressed in epithelial cells, defensinlike peptides (elafin and secretory leukocyte protease inhibitor) are of epithelial and leukocyte origin. ${ }^{7}$ These molecules have similar biochemical properties such as low molecular mass, cationic charge, and disulfide bonds. In their function as serine protease inhibitors, elafin and secretory leukocyte protease inhibitor seem to be critical in maintaining tissue integrity by antagonizing aggressive serine proteases such as human neutrophil elastase. ${ }^{8}$ In addition, they serve as antimicrobials with a broad spectrum against Gram-positive and Gramnegative bacteria, selected fungi, as well as different viruses. ${ }^{7}$ Another antimicrobial peptide mostly directed toward Gramnegative bacteria is bactericidal/permeability-increasing protein. Functional studies revealed that epithelial bactericidal/ permeability-increasing protein contributes significantly to lipid-mediated bacterial killing and the attenuation of bacterial-elicited proinflammatory signals. ${ }^{9,10}$

In the intestinal tract, defensins help regulate the composition and number of colonizing microbes, and protect the host from food-borne and water-borne pathogens. The proposed physiological functions of the intestinal defensins can be grouped into different overlapping categories. In the large intestine, the physiology is different from the small intestine, mostly because of the very high density of colonizing microbes. ${ }^{11}$ It is remarkable that the infections and translocations across the colonic mucosa by these bacteria are uncommon, considering that an epithelium with a single cell layer separates the bowel from the microbe-laden lumen. A leading hypothesis holds that the colon is a complex ecosystem with dynamic interactions between dense resident microflora, the colonic epithelial cells, and the classical immune cells. ${ }^{12}$ When the ecosystem is in balance, epithelial cells prevent microbial invasion by providing 
Table 1 Antimicrobial peptide expression in UC, colonic CD, and ileal CD

\begin{tabular}{ll}
\hline UC (colon) & CD (colon) \\
\hline - Normal expression of $\beta$-defensin HBD1 & - Attenuated induction of $\beta$-defensins \\
$\begin{array}{l}\text { and regular induction of HBD2, HBD3, } \\
\text { and HBD4 }\end{array}$ & HBD2, HBD3, and HBD4 \\
- $\begin{array}{l}\text { Bttenuated induction of antimicrobial } \\
\text { antiproteases Elafin and SLPI } \\
\text { HBD1 }\end{array}$ & Borderline decreased expression \\
- Regular induction of antimicrobial & of HBD1 \\
$\quad \begin{array}{l}\text { antiproteases Elafin and SLPI } \\
\text { - Regular induction of cathelicidin LL37 }\end{array}$ & - Attenuated induction of cathelicidin \\
- HD5 and HD6 expression because & - HD5 and HD6 expression because \\
of metaplastic Paneth cells & Of metaplastic Paneth cells \\
- Regular induction of BPI & - Regular induction of BPI
\end{tabular}

CD (ileum)

- Specific reduction of ileal Paneth-cell defensins(HD5 and HD6), even more pronounced in patients with a NOD2 mutation (in both cases independent of the grade of histological inflammation and not observed in inflammatory controls)

- Regular induction of BPI

Overall reduced mucosal antibacterial activity toward different bacteria

\section{Overall reduced mucosal antibacterial} activity toward different bacteria

BPI, bactericidal/permeability-increasing protein; CD, Crohn's disease; HBD, human $\beta$-defensin; NOD2, nucleotide-binding oligomerization domain 2; SLPI, secretory leukocyte protease inhibitor; UC, ulcerative colitis.

Implications resulting from functional observations are in bold.

a strong chemomechanical barrier, including the constitutive human $\beta$-defensin (HBD) 1 . $^{13}$ As a kind of "demand system" during inflammation or infection, the synthesis of additional defensins and other antimicrobial peptides is getting induced. In the latter case, defensins may prevent further bacterial entry into an already compromised epithelium and contribute to antimicrobial defense during inflammation at this site. Thus, it may be of relevance that the HBD2 is regulated by nuclear factor$\kappa \mathrm{B}$-dependent pathways, because this transcription factor also regulates many proinflammatory cytokines. ${ }^{14}$ Paneth-cell metaplasia at various sites of inflammation along the gastrointestinal tract $^{15-17}$ seems to be an alternative "on-demand" mechanism that provides antimicrobial expression and protection.

In contrast, the number of bacteria is very low in the small intestinal tract. This seems to be because, at least in part, of the extremely abundant constitutive expression of $\alpha$-defensins, which are expressed by crypt Paneth cells ${ }^{3}$ with almost exclusive physiological expression in the small intestine. ${ }^{18}$ It should be emphasized that the exceptional expression of metaplastic Paneth cells (mentioned above) throughout the intestinal tract occurs at much lower levels. In addition, the Paneth-cell defensins regulate the composition and number of luminal colonizing microbes present in the small intestine, ${ }^{19}$ and protect against pathogens. ${ }^{20,21}$ Paneth-cell antimicrobials, which are stored in secretory granules, are released into the intestinal lumen on stimulation with bacterial products including lipopolysaccharide and muramyl dipeptide, ${ }^{22}$ the specific ligand of nucleotide-binding oligomerization domain 2 (NOD2). ${ }^{23}$

\section{DEFENSINS IN CROHN'S DISEASE AND ULCERATIVE COLITIS}

Inflammatory bowel disease is a chronic inflammation of the intestine. On the basis of its clinical features and histopathology, it is often grouped into two major entities, ulcerative colitis (UC) and CD. In both forms of IBD, intestinal commensal microbiota are thought to trigger the disease in genetically susceptible individuals. Although the inflammation seen in patients with UC is typically restricted to the colon, that of CD occurs at many sites, most commonly in the small intestinal ileum and in the colon. ${ }^{24}$ Our hypothesis of the key mechanism leading to CD is on the basis of slow bacterial invasion because of compromised defense by mucosal peptide antibiotics including defensins. This concept is on the basis of patient and confirmative mouse data and is not mutually exclusive to other more classical explanations that hypothesize mostly about a suggested primary function of a possibly dysregulated adaptive immune system. Approximately one-third of patients with CD have a mutation in the NOD2 gene that encodes an intracellular bacterial pattern-recognition receptor (for a very recent review see ref. 25). Further clinical analyses have revealed that this mutation is associated with the clinical phenotype of ileal CD but not with the colonic type of CD (for review see refs. 26,27). Recent lines of investigations demonstrated that these different clinical localizations of CD are associated with different deficiencies in epithelial and leukocyte antimicrobial peptide expression and function ${ }^{28}$ (Tables 1 and 2). As compared with UC, CD of the colon is characterized by an impaired induction of antimicrobial antiproteases elafin and secretory leukocyte protease inhibitor, ${ }^{29}$ the cathelicidin LL-37, ${ }^{30}$ and most importantly $\beta$-defensins. ${ }^{31-34}$ As a consequence of the attenuated expression of antimicrobials, the colonic mucosa is compromised in their killing capacity toward different commensal bacteria. In contrast, ileal CD patients are characterized by a reduced antibacterial activity and a specific reduction of ileal Paneth-cell defensins. This decrease is independent of the grade of histological inflammation and cannot be found in inflammation controls such as UC ileitis in pouch (after colorectal removal). ${ }^{19,35}$ Some of these defects can be explained either by direct or by indirect genetic mechanisms and appear to be primary. In the following, we will describe some of the known mechanisms that provide insights into relevant regulation of these antimicrobial defense molecules.

\section{MECHANISMS OF $\beta$-DEFENSIN DEFICIENCY: GENE COPY NUMBER AND SINGLE-NUCLEOTIDE POLYMORPHISMS}

HBD1 was the first defensin to be identified in the human large bowel and initially thought to be expressed constitutively. ${ }^{13}$ To date, it is the only defensin known to be permanently expressed 


\section{Table 2 Overview of peer reviewed data on Paneth cell $\alpha$-defensins and small intestinal inflammatory disease in different cohorts}

Decreased expression of Paneth cell defensins in ileal CD (independent of NOD2)

\begin{tabular}{lll}
\hline $\begin{array}{l}\text { German cohort I, } \\
\text { different centers } \\
\text { in Germany }\end{array}$ & Gut, 2004 & Gene expression \\
$\begin{array}{l}\text { US cohort I, Cleveland } \\
\begin{array}{l}\text { Clinic Foundation } \\
\text { patients }\end{array}\end{array}$ & $\begin{array}{l}\text { Proc. Natl. Acad. } \\
\text { Sci. USA, 2005 }\end{array}$ & $\begin{array}{l}\text { Gene expression } \\
\text { and Protein }\end{array}$ \\
$\begin{array}{l}\text { German cohort II, } \\
\text { Stuttgart }\end{array}$ & J. Immunol., 2007 & $\begin{array}{l}\text { Gene expres- } \\
\text { sion, promoter } \\
\text { binding } \\
\text { activity }\end{array}$ \\
UK cohort, Nottingham & J. Pathol., 2008 & $\begin{array}{l}\text { HD5 protein in } \\
\text { ileostomy fluid }\end{array}$
\end{tabular}

Decreased expression associated with NOD2 mutation

\begin{tabular}{|c|c|c|}
\hline $\begin{array}{l}\text { German cohort I, } \\
\text { different centers in } \\
\text { Germany }\end{array}$ & Gut, 2004 & $\begin{array}{l}\text { Ileal and colonic } \\
\text { gene expression }\end{array}$ \\
\hline $\begin{array}{l}\text { US cohort I, Cleveland } \\
\text { Clinic Foundation } \\
\text { patients }\end{array}$ & $\begin{array}{l}\text { Proc. Natl. Acad. } \\
\text { Sci. USA, } 2005\end{array}$ & $\begin{array}{l}\text { Gene expres- } \\
\text { sion and pro- } \\
\text { tein (1007fs } \\
\text { (frameshift)) }\end{array}$ \\
\hline $\begin{array}{l}\text { NOD2 knockout mice, } \\
\text { New Haven, USA }\end{array}$ & Science, 2005 & Gene expression \\
\hline $\begin{array}{l}\text { US cohort II, } \\
\text { Georgetown University }\end{array}$ & Gut, 2008 & $\begin{array}{l}\text { Gene expression } \\
\text { and protein }\end{array}$ \\
\hline UK cohort, Nottingham & J. Pathol., 2008 & HD5 protein \\
\hline
\end{tabular}

Decrease of Paneth cell defensins is independent of inflammation

\begin{tabular}{|c|c|c|}
\hline $\begin{array}{l}\text { German cohort I, } \\
\text { different centers }\end{array}$ & Gut, 2004 & $\begin{array}{l}\text { Expression of } \\
\text { molecular } \\
\text { markers within } \\
\text { CD groups }\end{array}$ \\
\hline $\begin{array}{l}\text { US cohort I, Cleveland } \\
\text { Clinic Foundation } \\
\text { patients }\end{array}$ & $\begin{array}{l}\text { Proc. Natl. Acad. } \\
\text { Sci. USA, } 2005\end{array}$ & $\begin{array}{l}\text { Expression of } \\
\text { molecular mark- } \\
\text { ers, histological } \\
\text { grading, gene } \\
\text { expression } \\
\text { in UC ileitis } \\
\text { (Pouchitis) }\end{array}$ \\
\hline $\begin{array}{l}\text { German cohort II, } \\
\text { Stuttgart }\end{array}$ & J. Immunol., 2007 & $\begin{array}{l}\text { Expression of } \\
\text { molecular } \\
\text { markers }\end{array}$ \\
\hline German cohort, Kiel & $\begin{array}{l}\text { World J. } \\
\text { Gastroenterol., } \\
2006\end{array}$ & $\begin{array}{l}\text { Gene expres- } \\
\text { sion in UC ileitis } \\
\text { (Pouchitis) }\end{array}$ \\
\hline UK cohort, Nottingham & Am. J. Pathol., 2008 & $\begin{array}{l}\text { HD5 peptide } \\
\text { levels in ileos- } \\
\text { tomy fluid }\end{array}$ \\
\hline
\end{tabular}

Functional changes/decreased killing of mucosa

\begin{tabular}{lll}
\hline HD5 transgenic mice, & Proc. Natl. Acad. & Composition of \\
Davis, Milwaukee & Sci. USA, 2005 & $\begin{array}{l}\text { luminal bacterial } \\
\text { flora }\end{array}$
\end{tabular}

Table 2 Continued

\begin{tabular}{lll}
\hline $\begin{array}{l}\text { TCF4 +l- knockout } \\
\text { mice, Stuttgart, Utrecht }\end{array}$ & J. Immunol., 2007 & $\begin{array}{l}\text { Gene } \\
\text { expression and } \\
\text { mucosal killing } \\
\text { activity }\end{array}$ \\
German cohort III & $\begin{array}{l}\text { Proc. Natl. Acad. } \\
\text { Sci. USA, 2005 }\end{array}$ & $\begin{array}{l}\text { Mucosal killing } \\
\text { activity in CD } \\
\text { patients }\end{array}$ \\
Impaired processing of HD5 peptide & Biochem. Biophys. & HD5 protein in \\
Japanese cohort, & $\begin{array}{l}\text { Res. Commun., } \\
\text { Asahikawa Medical }\end{array}$ & 2007 patients \\
$\begin{array}{l}\text { College } \\
\text { UK cohort, Nottingham }\end{array}$ & Am. J. Pathol., 2008 & $\begin{array}{l}\text { HD5 protein in } \\
\text { CD patients }\end{array}$ \\
\hline
\end{tabular}

CD, Crohn's disease; NOD2, nucleotide-binding oligomerization domain 2; UC, ulcerative colitis.

in the uninflamed colon. Expression of HBD1 mRNA seems to be slightly reduced in the inflamed tissue of patients with IBD. ${ }^{31,32}$ In contrast to HBD1, the inducible $\beta$-defensin HBD2 is absent from the healthy colon. ${ }^{14}$ Several studies have investigated the expression of HBD2 in UC, finding a strong induction in case of inflammation. ${ }^{14,31-33}$ When comparing colonic HBD2 expression among patients with CD and UC, there is a striking difference: a strong HBD2 induction is observed in UC patients, whereas this induction seems to be attenuated in the inflamed tissue of CD patients. ${ }^{31,32}$ Two $\beta$-defensins with a different antimicrobial spectrum, $\mathrm{HBD} 3$ and $\mathrm{HBD} 4$, seem to follow this distribution pattern, although their mRNA expression levels are lower. ${ }^{31,34}$

Crohn's disease of the colon is among the first diseases, with a known association of lower expression of a gene cluster. ${ }^{36}$ Notably, the DNA copy number of the $\beta$-defensin gene cluster on chromosome 8p23.1 is highly polymorphic within the healthy population, which suggested that the defective $\beta$-defensin induction in colonic CD could be because of low $\beta$-defensin gene copy number. We recently tested this hypothesis, using genome-wide DNA copy number profiling by array-based comparative genomic hybridization and quantitative PCR analysis of the HBD2 gene. We showed that healthy individuals, as well as patients with UC, have a median of four (range 2-10) HBD2 gene copies per diploid genome. In a surgical cohort with ileal or colonic CD and in a second large cohort with IBDs, those with ileal resections/disease exhibited a normal median $H B D 2$ copy number of four, whereas those with colonic CD had a median of only three copies per genome. Overall, the copy number distribution in colonic CD was shifted to lower numbers compared with controls. Individuals with $\leqslant 3$ copies have a significantly higher risk of developing colonic CD than did the individuals with $\geqslant 4$ copies (odds ratio 3.06; $95 \%$ confidence interval 1.46-6.45). An HBD2 gene copy number of $<4$ was associated with diminished mucosal HBD2 mRNA expression. In conclusion, a lower HBD2 gene copy number in the $\beta$-defensin locus predisposes to colonic $\mathrm{CD}$, most likely through diminished $\beta$ defensin expression. As $H B D 3$ and $H B D 4$ are on the same gene locus, it is likely that the expression pattern of these other inducible $\beta$-defensins is because of the same mechanism. 
In addition to changes in the gene number, very recently Kocsis et al. ${ }^{37}$ showed different single-nucleotide polymorphisms of $H B D 1$ associated with colonic $C D$. One single-nucleotide polymorphism associated with a higher risk for colonic, but not ileal, disease revealed an odds ratio of 2.39, whereas another single-nucleotide polymorphism was found more frequently in controls and thus appears to be protective. This is the first report demonstrating a primary function of HBD1 even though confirmatory studies in other cohorts are still needed. ${ }^{37}$

To test possible functional consequences of this deficiency, we investigated the antimicrobial activity in colonic mucosa from patients with IBD and healthy controls. For this, we established a flow cytometric assay to quantitate bacterial killing ${ }^{38}$ and tested the antibacterial activity of cationic peptide extracts from colonic biopsies taken from patients with active or inactive ileocolonic or colonic CD, UC, and controls against clinical isolates of different bacteria (including Bacteroides vulgatus, Enterococcus fecalis as well as reference strains of Escherichia coli and Staphylococcus aureus). Consistent with the earlier findings, there was a reduced antimicrobial effect in CD extracts, which was most evident against B. vulgatus. ${ }^{39}$ Also, the antimicrobial effect against $E$. coli and $E$. fecalis was significantly lower in CD compared with UC. Activity against $S$. aureus disclosed a similar pattern although less pronounced. The differences were independent from the inflammation status or concurrent steroid treatment. Bacteria incubated with biopsy extracts from UC patients showed frequently a characteristic change in cell size and granularity, compatible with more extensive membrane disintegration, compared with bacteria incubated with extracts from controls or $\mathrm{CD}$. Thus, $\mathrm{CD}$ of the colon, similar to that in the small intestine, is characterized by a diminished functional antimicrobial activity ${ }^{19,39}$ that is consistent with the reported low antibacterial peptide expression.

\section{MECHANISMS OF PANETH-CELL $\alpha$-DEFENSIN DEFICIENCY Defect in detecting microbes (pattern recognition receptor NOD2)}

In the small intestinal mucosa, NOD2 is expressed in Paneth cells, which is consistent with a possible function for Panethcell antimicrobials in $\mathrm{CD}^{28}$ Independent studies in humans and a rodent model substantiate a link between NOD2 mutations, Paneth-cell defensins and CD. ${ }^{19,40,41}$ A decrease of the Paneth-cell $\alpha$-defensins human defensins 5 and 6 (HD5 and HD6), mRNA, and protein has been shown in patients with $\mathrm{CD}$ of the small intestinal ileum. Interestingly, even though essentially all patients with ileal CD had diminished HD5 and HD6 levels, this decrease was most pronounced in patients with an NOD2 mutation. In the same patients the mRNA expression levels of proinflammatory cytokines, tumor necrosis factor- $\alpha$ and interleukin- 8 were independent of NOD2 status. By contrast, ileal levels of Paneth-cell $\alpha$-defensins from patients with $\mathrm{CD}$ of the colon were unchanged. In a further study in German and US patient populations, the decreased expression of Paneth-cell $\alpha$-defensins was confirmed both for mRNA and protein, whereas the expression of other Paneth-cell products either remained unchanged or increased when compared with controls. ${ }^{19}$ The specific decrease of $\boldsymbol{\alpha}$-defensins was independent of the degree of inflammation in the specimens and was not observed in CD of the colon, UC, or most importantly pouchitis, as an inflammatory control of nonCrohn's ileitis. The functional consequence of the low $\alpha$-defensin levels was a diminished antibacterial activity in ileal mucosal extracts. ${ }^{19}$ These data were just confirmed by Elphick et. al. ${ }^{42}$ in a UK cohort showing a decrease of Paneth-cell defensin-5 peptide levels in $\mathrm{CD}$, which was even more pronounced in case of NOD2 mutation. In addition, the authors suggest a disturbed luminal processing of HD5 from the immature to the mature form of the peptide, which is consistent with previous reports from Japanese patients. ${ }^{43}$

In a subsequent study using a rodent model, Kobayashi and colleagues reported a decrease of Paneth-cell $\alpha$-defensin (cryptidin) mRNA expression in mice lacking the NOD2 gene. ${ }^{41}$ The NOD2 knockout mice were unable to detect muramyl dipeptide, the ligand for NOD2. Most interestingly, these mice were more susceptible to an oral, but not systemic, infection with the pathogenic bacterium Listeria monocytogenes, supporting the importance of NOD2 in epithelial antimicrobial function. ${ }^{41}$ Taken together, these results suggest that there is a link between NOD2 function and $\alpha$-defensin expression, but the mechanistic details are still obscure. Furthermore, the studies of patients with ileal CD suggest that reduced Paneth-cell defensins is ultimately linked to the disease. Possibly, inadequate activation of proHD-5 is another mechanism contributing to compromised antibacterial activity. ${ }^{42,43}$

\section{NOD2-mediated innate immunity in graft vs. host reaction}

Another recent fascinating study on small intestinal transplantation supports and significantly extends our understanding of NOD2-mediated innate immunity. Intestinal allograft rejection resembles CD clinically and pathologically. From the studies by Holler et al. ${ }^{44}$ from Regensburg, Germany, it is known that NOD2 mutations have a significant impact on survival after organ transplantation. Now, the authors around Fishbein and Zasloff ${ }^{45}$ from Georgetown aimed to determine whether epithelial immune function and graft survival were influenced by NOD2 mutations in an intestinal transplant population. They assessed NOD2 genotypes of 34 transplants and tested if clinical outcomes together with the expression of protective intestinal antimicrobial defensins were altered. Consistent with the study by Holler et al., ${ }^{44}$ the likelihood of allograft failure was much higher (approximately 100\%) in recipients with mutant NOD2 alleles compared with recipients with wild-type NOD2 loci. Consistent with the observations in CD patients, NOD2 knockout mice, and cell cultures, ${ }^{46}$ rejection in NOD2 mutant recipients was characterized by specifically decreased expression of Paneth-cell defensin HD5, as well as enterocyte human $\beta$-defensin. Most importantly, this decrease was found before the onset of epithelial injury and inflammation, which also reflects earlier observations. In contrast to NOD2-mediated epithelial graft vs. host reaction, defensins were unchanged in NOD2 wild-type patients, which strongly supports that the decrease is primary and not an effect of inflammation itself. ${ }^{45}$ 
Epithelial stem cell differentiation mediated by Wnt signaling As mentioned above, NOD2 mutations provide one relevant mechanism for the decrease of Paneth-cell defensins. As this decrease is found in essentially all patients with ileal disease and only approximately one-third have NOD2 mutations, there must be other mechanisms. Paneth cells derive from a compartment of progenitor cells located just above their crypt base location. Accordingly, their migration from these stem cells is downward as opposed to the upward migration of the absorptive epithelial cells toward the villus tip. Wnt signaling, which can be transduced through $\beta$-catenin/T-cell-specific transcription factor 4 (TCF4), has been shown to maintain the undifferentiated state of the progenitor cells ${ }^{47}$ and, paradoxically, also induces maturation of Paneth cells in intestinal crypts. ${ }^{48}$ In elegant studies, the group of Clevers ${ }^{48}$ in Utrecht clearly demonstrated that a Paneth-cell gene program is critically dependent on TCF4 embryonic mouse intestine. This pathway is also disturbed in ileal CD patients. ${ }^{49}$ We recently reported a reduced expression in ileal CD of the Wnt-signaling pathway transcription factor, TCF4, a known regulator of Paneth-cell differentiation. Within specimens, the levels of TCF4 mRNA showed a high degree of correlation with both HD5 and HD6 mRNA. The levels of TCF4 mRNA were decreased in patients with ileal disease irrespective of degree of inflammation, but were not decreased in colonic CD or UC. As a functional indicator of TCF4 protein, quantitative binding analysis with nuclear extracts from small intestinal biopsies to a TCF4 high-affinity binding site in the HD-5 and HD-6 promoters showed significantly reduced activity in ileal CD. Furthermore, a causal link was shown in a murine TCF4 knockout model, where the comparably reduced expression of TCF4 in heterozygous $(+/-)$ mice was sufficient to cause a significant decrease of both Paneth-cell $\alpha$-defensin levels and bacterial killing activity. Notably, the association between Paneth-cell $\alpha$-defensins and TCF4 was found to be independent of NOD2 genotype. This new link established between a human IBD and the Wnt pathway/TCF4 provides a novel mechanism for pathogenesis in patients with ileal CD. ${ }^{49}$

\section{THERAPEUTIC CONSEQUENCES}

We believe that the knowledge about defensins and other antimicrobial peptides will have a substantial influence on future therapeutic strategies. For the treatment of IBD, strategies might aim to strengthen protective innate immunity, rather than just blocking a mostly secondary response. Some interesting experimental observations leave room for speculation. For example, zinc depletion has a crucial impact on Paneth-cell integrity and antimicrobial function. ${ }^{50,51}$ Conversely, supplementation with zinc significantly reduces mortality in childhood diarrhea. ${ }^{52}$ A possible explanation for this clinical observation is that zinc may bolster Paneth-cell function by as yet unknown mechanisms.

As discussed above, Paneth cell-derived antimicrobials are decreased in patients with ileal CD. In this context, the reported efficiency of Trichuris suis therapy in CD provokes the testable question of whether the stimulation of Paneth-cell defensins by parasitic worms might be an explanation for their therapeutic effect. ${ }^{53}$ Probiotic bacteria such as E. coli Nissle 1917 and Lactobacilli have been shown to induce antimicrobial peptides strongly. ${ }^{54}$ In case of $E$. coli Nissle, this induction is mediated by a specific Flagellin, ${ }^{55}$ and further work will elucidate additional stimulators in other strains. E. coli Nissle 1917 (Mutaflor) is the oldest known (in use since World War I, 1917) and probably the best-studied probiotic strain. Its efficacy in maintaining remission in UC (as effective as standard treatment with mesalazine) has been shown in different placebo-controlled, double-blinded studies, and this strain is now recommended as a guideline therapy by the Deutsche Gesellschaft für Gastroenterologie. ${ }^{56-58}$ Even though this strain is clearly effective in UC (and probably other probiotics too), probiotic treatment in CD seems to be limited and less useful. A possible but speculative explanation could be a general defect in the upregulation of defensins and other protective host molecules. We believe that this might be an important mechanism to help the mucosa to prevent bacterial invasion. Probiotic bacteria are the first therapeutic agents for IBD that are known to bolster the production of antimicrobial peptides but it is likely that other therapeutic agents such as worm eggs, specific bacterial food, or artificial components could have similar effects.

\section{CONCLUSION}

By today, different mechanisms have been described that explain why a broad variety of antimicrobial peptides show an impaired expression at different disease locations of CD. Almost 100 years after the pioneer Fleming described antibiotic activity of lysozyme in mucosal secretions, the paramount importance of other antimicrobial peptides is becoming slowly accepted. The gastrointestinal tract is a particularly critical site because it has a large surface area that is heavily colonized with microbes. Defensins and other antimicrobial peptides provide a critical mucosal defense. Defensins have a potent protective activity against a wide range of microbes and can also signal to the various components of the innate and adaptive immune systems. A complex and finely tuned system of regulation and function of intestinal antimicrobial peptides probably contributes to the maintenance and balance of commensal flora in a healthy gut. Disruption of this critical balance could lead to gastrointestinal infection and disease. We believe that this knowledge will result in new therapeutic avenues in the near future.

\section{DISCLOSURE}

All authors have declared no financial interests.

(C) 2008 Society for Mucosal Immunology

\section{REFERENCES}

1. Zasloff, M. Antimicrobial peptides of multicellular organisms. Nature 415, 389-395 (2002).

2. Dommett, R., Zilbauer, M., George, J.T. \& Bajaj-Elliott, M. Innate immune defence in the human gastrointestinal tract. Mol. Immunol. 42, 903-912 (2005).

3. Bevins, C.L. The Paneth cell and the innate immune response. Curr. Opin. Gastroenterol. 20, 572-580 (2004). 
4. Wehkamp, J., Fellermann, K., Herrlinger, K., Bevins, C. \& Stange, E.F. Mechanisms of disease: defensins in gastrointestinal diseases. Nat. Clin Pract.: Gastroenterol. Hepatol. 2, 406-415 (2005).

5. Wehkamp, J., Schmid, M. \& Stange, E.F. Defensins and other antimicrobial peptides in inflammatory bowel disease. Curr. Opin. Gastroenterol. 23, 370-378 (2007).

6. Boman, H.G. Peptide antibiotics and their role in innate immunity. Annu. Rev. Immunol. 13, 61-92 (1995).

7. Sallenave, J.M. Antimicrobial activity of antiproteinases. Biochem. Soc. Trans. 30, 111-115 (2002).

8. Hiemstra, P.S. Novel roles of protease inhibitors in infection and inflammation. Biochem. Soc. Trans. 30, 116-120 (2002).

9. Canny, G. et al. Functional and biochemical characterization of epithelial bactericidal/permeability-increasing protein. Am. J. Physiol. Gastrointest. Liver Physiol. 290, G557-G567 (2006).

10. Canny, G. et al. Lipid mediator-induced expression of bactericidal/ permeability-increasing protein (BPI) in human mucosal epithelia. Proc. Natl. Acad. Sci. USA 99, 3902-3907 (2002).

11. Simon, G.L. \& Gorbach, S.L. Normal alimentary tract microflora. In Infections of the Gastrointestinal Tract (Blaser, M.J., Smith, P.D., Ravdin H.B., Greenberg, R.L. \& Guerrant, R.L., eds) 53-69 (Raven Press, New York, 1995)

12. McCracken, V.J. \& Lorenz, R.G. The gastrointestinal ecosystem: a precarious alliance among epithelium, immunity and microbiota. Microreview. Cell. Microbiol. 3, 1-11 (2001).

13. Zhao, C., Wang, I. \& Lehrer, R.I. Widespread expression of beta-defensin hBD-1 in human secretory glands and epithelial cells. FEBS Lett. 396, 319-322 (1996)

14. O'Neil, D.A. et al. Expression and regulation of the human $\beta$-defensins hBD-1 and hBD-2 in intestinal epithelium. J. Immunol. 163, 6718-6724 (1999).

15. Cunliffe, R.N. et al. Human defensin 5 is stored in precursor form in normal Paneth cells and is expressed by some villous epithelial cells and by metaplastic Paneth cells in the colon in inflammatory bowel disease. Gut 48, 176-185 (2001).

16. Wehkamp, J. et al. Defensin pattern in chronic gastritis: HBD-2 is differentially expressed with respect to Helicobacter pylori status. J. Clin. Pathol. 56, 352-357 (2003).

17. Shen, B. et al. Human defensin 5 expression in intestinal metaplasia of the upper gastrointestinal tract. J. Clin. Pathol. 58, 687-694 (2005).

18. Wehkamp, J. et al. Paneth cell antimicrobial peptides: topographical distribution and quantification in human gastrointestinal tissues. FEBS Lett. 580, 5344-5350 (2006).

19. Wehkamp, J. et al. Reduced Paneth cell alpha-defensins in ileal Crohn's disease. PNAS 102, 18129-18134 (2005).

20. Porter, E.M., Bevins, C.L., Ghosh, D. \& Ganz, T. The multifaceted Paneth cell. Cell Mol. Life Sci. 59, 156-170 (2002).

21. Salzman, N.H., Ghosh, D., Huttner, K.M., Paterson, Y. \& Bevins, C.L. Protection against enteric salmonellosis in transgenic mice expressing a human intestinal defensin. Nature 422, 522-526 (2003).

22. Ayabe, T. et al. Secretion of microbicidal alpha-defensins by intestinal Paneth cell response to bacteria. Nat. Immunol. 1, 113-118 (2000).

23. Inohara, N., Chamaillard, M., McDonald, C. \& Nunez, G. NOD-LRR proteins: role in host-microbial interactions and inflammatory disease. Annu. Rev. Biochem. 19, 355-383 (2005).

24. Podolsky, D.K. Inflammatory bowel disease. N. Engl. J. Med. 347, 417-429 (2002).

25. Wilmanski, J.M., Petnicki-Ocwieja, T. \& Kobayashi, K.S. NLR proteins: integral members of innate immunity and mediators of inflammatory diseases. J. Leukoc. Biol. 83, 13-30 (2008).

26. Gasche, C. \& Grundtner, P. Genotypes and phenotypes in Crohn's disease: do they help in clinical management? Gut 54, 162-167 (2005)

27. Schreiber, S., Rosenstiel, P., Albrecht, M., Hampe, J. \& Krawczak, M. Genetics of Crohn disease, an archetypal inflammatory barrier disease. Nat. Rev. Genet. 6, 376-388 (2005).

28. Wehkamp, J., Schmid, M., Fellermann, K. \& Stange, E.F. Defensin deficiency, intestinal microbes, and the clinical phenotypes of Crohn's disease. J. Leukoc. Biol. 77, 460-465 (2005).
29. Schmid, M. et al. Attenuated induction of epithelial and leukocyte serine antiproteases elafin and secretory leukocyte protease inhibitor in Crohn's disease. J. Leukoc. Biol. 81, 907-915 (2007).

30. Schauber, J. et al. Heterogeneous expression of human cathelicidin hCAP18/LL-37 in inflammatory bowel diseases. Eur. J. Gastroenterol. Hepatol. 18, 615-621 (2006).

31. Wehkamp, J. et al. Inducible and constitutive beta-defensins are differentially expressed in Crohn's disease and ulcerative colitis. Inflamm. Bowel. Dis. 9, 215-223 (2003).

32. Fahlgren, A., Hammarstrom, S., Danielsson, A. \& Hammarstrom, M.L. Increased expression of antimicrobial peptides and lysozyme in colonic epithelial cells of patients with ulcerative colitis. Clin. Exp. Immunol. 131, 90-101 (2003).

33. Wehkamp, J. et al. Human beta-defensin 2 but not beta-defensin 1 is expressed preferentially in colonic mucosa of inflammatory bowel disease. Eur. J. Gastroenterol. Hepatol. 14, 745-752 (2002).

34. Fahlgren, A., Hammarstrom, S., Danielsson, A. \& Hammarstrom, M.L. Beta-Defensin-3 and -4 in intestinal epithelial cells display increased mRNA expression in ulcerative colitis. Clin. Exp. Immunol. 137, 379-385 (2004).

35. Kiehne, K. et al. Defensin expression in chronic pouchitis in patients with ulcerative colitis or familial adenomatous polyposis coli. World $\mathrm{J}$. Gastroenterol. 12, 1056-1062 (2006).

36. Fellermann, K. et al. A chromosome 8 gene-cluster polymorphism with low human beta-defensin 2 gene copy number predisposes to Crohn disease of the colon. Am. J. Hum. Genet. 79, 439-448 (2006).

37. Kocsis, AK et al. Association of beta-defensin 1 single nucleotide polymorphisms with Crohn's disease. Scand. J. Gastroenterol. 18, 1-9 (2007).

38. Nuding, S., Fellermann, K., Wehkamp, J., Mueller, H.A. \& Stange, E.F. A flow cytometric assay to monitor antimicrobial activity of defensins and cationic tissue extracts. J. Microbiol. Methods 65, 335-345 (2006).

39. Nuding, S., Fellermann, K., Wehkamp, J. \& Stange, E.F. Reduced mucosal antimicrobial activity in Crohn's disease of the colon. Gut 56, 1240-1247 (2007)

40. Wehkamp, J. et al. NOD2 (CARD15) mutations in Crohn's disease are associated with diminished mucosal a-defensin expression. Gut $\mathbf{5 3}$ 1658-1664 (2004)

41. Kobayashi, K.S. et al. Nod2-dependent regulation of innate and adaptive immunity in the intestinal tract. Science 307, 731-734 (2005).

42. Elphick, D., Liddell, S. \& Mahida, Y.R. Impaired luminal processing of human defensin- 5 in crohn's disease: persistence in a complex with chymotrypsinogen and trypsin. Am. J. Pathol. 172, 702-713 (2008).

43. Tanabe, H. et al. Denatured human alpha-defensin attenuates the bactericidal activity and the stability against enzymatic digestion. Biochem. Biophys. Res. Commun. 358, 349-355 (2007).

44. Holler, E. et al. Prognostic significance of NOD2/CARD15 variants in HLA-identical sibling hematopoietic stem cell transplantation: effect on long-term outcome is confirmed in 2 independent cohorts and may be modulated by the type of gastrointestinal decontamination. Blood 107 , 4189-4193 (2006)

45. Fishbein, T. et al. NOD2-expressing bone marrow-derived cells appear to regulate epithelial innate immunity of the transplanted human small intestine. Gut 57, 323-330 (2008).

46. Voss, E. et al. NOD2/CARD15 mediates induction of the antimicrobial peptide human beta-defensin-2. J. Biol. Chem. 281, 2005-2011 (2006).

47. Gregorieff, A. \& Clevers, H. Wnt signaling in the intestinal epithelium: from endoderm to cancer. Genes Dev. 19, 877-890 (2005).

48. van Es, J.H. et al. Wnt signalling induces maturation of Paneth cells in intestinal crypts. Nat. Cell Biol. 7, 381-386 (2005).

49. Wehkamp, J. et al. The paneth cell alpha-defensin deficiency of ileal Crohn's disease is linked to Wnt/Tcf-4. J. Immunol. 179, 3109-3118 (2007).

50. Otto, H.F. \& Weitz, H. [Electron microscopy studies of Paneth cells in rats fed with zinc deficient diet]. Beitr. Pathol. 145, 336-349 (1972).

51. Cousins, R.J. A role of zinc in the regulation of gene expression. Proc. Nutr. Soc. 57, 307-311 (1998).

52. Sazawal, S. et al. Zinc supplementation in young children with acute diarrhea in India. N. Engl. J. Med. 333, 839-844 (1995). 


\section{REVIEW}

53. Summers, R.W., Elliott, D.E., Urban, J.F. Jr., Thompson, R. \& Weinstock, J.V. Trichuris suis therapy in Crohn's disease. Gut 54, 87-90 (2005).

54. Wehkamp, J. et al. NF-kB and AP-1 mediated induction of human beta defensin-2 in intestinal epithelial cells by E. coli Nissle 1917: a novel effect of a probiotic bacterium. Infect. Immun. 72, 5750-5758 (2004).

55. Schlee, M. et al. The induction of human beta-defensin-2 by the probiotic Escherichia coli nissle 1917 is mediated through flagellin. Infect. Immun. 75, 2399-2407 (2007).
56. Kruis, W. et al. Double-blind comparison of an oral Escherichia coli preparation and mesalazine in maintaining remission of ulcerative colitis. Aliment. Pharmacol. Ther. 11, 853-858 (1997).

57. Kruis, W. et al. Maintaining remission of ulcerative colitis with the probiotic Escherichia coli Nissle 1917 is as effective as with standard mesalazine. Gut 53, 1617-1623 (2004).

58. Rembacken, B.J., Snelling, A.M., Hawkey, P.M., Chalmers, D.M. \& Axon, A.T. Non-pathogenic Escherichia coli vs. mesalazine for the treatment of ulcerative colitis: a randomised trial. Lancet 354, 635-639 (1999). 